\title{
Can an Underachiever Become Competitive? The Case of the Romanian Food Industry
}

\author{
Marian Liviu Mocan \\ Department of Management, Politehnica University from Timisoara, \\ Timisoara 300191 Romania \\ Email: marian.mocan@upt.ro (Corresponding Author) \\ Attila Turi \\ Department of Management, Politehnica University from Timisoara, \\ Timisoara 300191 Romania \\ Email: attila.turi@yahoo.com \\ Gilles Goncalves \\ Department of Informatics and Automation, Univ Lille Nord de France, \\ Lille 59000 France \\ E-mail: gilles.goncalves@univ-artois.fr \\ Sorin-Ioan Maistor \\ Department of Management, Politehnica University from Timisoara, \\ Timisoara 300191 Romania \\ Email: sorin.maistor@student.upt.ro
}

\begin{abstract}
The paper outlines current challenges in Romanian food industry, its potential to overcome them and be competitive on both the national and international market using a key performance indicator (KPI) methodology. Although it has the capacity to assure internal consumption and competition on the market is high the Romanian food sector is struggling to meet internal demand, imports heavily exceed exports while food consumption is decreasing. The retail sector is an important part of the supply chain, but the harsh competition among the different stores has made them pass the risks only towards the upstream links which is straining food processors and producers and threatening the sustainable development of the food supply chain. High taxation, unfair competition and delayed payments towards food processors add extra pressure on the weaker links of the chain. Moreover authorities are inefficient in assuring duly market conditions whereas scandals further degrade industry image and cause important losses. The lack of synergic efforts within the industry and the scarce collaboration efforts between business partners affect individual company performance and thus global industry competitiveness. The research provides solutions that address its structural issues and develops performance indicators to improve the efficiency of companies in order to assure their sustainable development within the supply chain and become more competitive on the global food.
\end{abstract}

Keywords: food industry, competitiveness, colaboration, supply chain, performance indicators

\section{INTRODUCTION}

Romania has a population of around 20 million people and is ranked second in Eastern Europe in terms of consumer market potential after Poland. The above European Union (EU) average growth rates of its Gross Domestic Product (GDP) before the financial crisis brought significant increases in consumption, food consumption included, rapidly developing the food sector. In 2008, only 10 years after the establishment of the first hypermarket in Romania, local and multinational retailers opened 134 stores with an invested value of nearly 600 million euros. The majority of these investments came from multinational retail groups like Kaufland, Auchan, Metro, Carrefour, Selgros and Billa. Today Romania's retail market accounts for more than 800 hypermarkets and supermarkets and is reaching saturation, with around 10 large retailers on the competitive landscape.

Food industry is an important sector in the Romanian economy, accounting for about a relatively stable $13.5 \%$ of industrial employment and $4.8 \%$ of total employment. The food and beverage industry employed more than 186,000 people in 2011 and generated a turnover of around 10 billion euros, representing a share of $8 \%$ in GDP.

The latest issues related to public health have reopened debates on food industry. Ahumada and Villalobos (2009) as well as Trienekens (2008) argue that food supply chains will be subject to more stringent regulations and closer monitoring in the near future and may bring about important changes to an already complex supply chain as endorsed by van Donk (2008). This in turn will shift the links of the food industry to not only work on their own internal performance and improve their efficiency according to Rong (2011), but also to operate an integrated approach throughout the entire 
chain by implicating all links from upstream to downstream in the industry. Meanwhile Lavie (2006) states that thus not only the individual companies will be able to prove themselves competitive, but the entire supply chain as well thus being capable of choosing appropriate strategies to better adapt to global conditions.

Romanian food industry is underperforming on both national and international level. Although EU accession has been beneficial, given its capability to produce and provide food products for internal consumption and exports the actual performance is disappointing thus making it an underachiever. Individual industry players have difficulties in assuring their profitability while the sustainability of their own supply chain is hindered by both internal and external factors. The purpose of this study is to analyze the challenges Romanian food industry is facing and the issues that hamper it to be competitive on national and international markets. Furthermore the research provides indicators that allow companies to regularly assess their performance and progress and enables a more sustainable perspective for them, their supply chain and the national food industry..

\section{RESEARCH GOALS AND METHODOLOGY}

A performance indicator or key performance indicator (KPI) makes objectives quantifiable, provides performance measurement and is a simple and useful tool for monitoring the performance of a key result area important to the success of the organization. For the measurement to be effective the levels that have to be achieved must be set according to certain company standards and represent challenging, yet realistic goals. Therefore choosing the right indicators depends on having a proper understanding of what is important to the company and its objectives as stated by Reh (2009).

As for the generation of the proposed performance indicators the methodology used was the guideline of the PROS 10/10 Strategic Management Standards of the Public Record Office Victoria Standards which is concerned with strategic management of public records and consists of strategy formulation, implementation and evaluation. The first step consists in gathering a sufficient amount of information and data on the subject and analyzing it for topic relevance as shown in the upper half of Figure 1. After some main ideas are highlighted, they need to be transformed into performance indicators and they have to pass the reality check (relevant, achievable, measurable, etc.) from the lower half of the figure. After all the information is compiled a list of indicators emerges by following the two stated steps above. For them to be effective, the indicators must address responsibilities, requirements and risks, and prompt the executive to proactively assess performance and address issues of noncompliances of any kind.

\section{RESULTS}

\subsection{The Negotiation Power of Retail Stores}

One of the most obvious weaknesses of the industry is related to the large number of small companies which compete with each other in the food market. Although this competition amongst them should be a source of competitiveness and performance improvement, it is actually a burden. Such a scarce concentration brings about low economies of scale, with a direct impact in cost control and overall performance. By adding both the low capacity utilisation and the low compliance with EU standards, the food industry shows its first major structural weakness according to the Romanian food sector and the use of EU Funds for Investments (2010). The low concentration of companies means that the effort to provide and distribute their goods towards consumers is considerably higher, less efficient and which not seldom accounts for a supply of local raw materials not fulfilling quantitative and qualitative requirements, due to the underdeveloped and disorganised agricultural sector. Romania's agricultural structure also faces the more delicate issue of land fragmentation as a result of the former state owned land being returned to previous owners. As the Romanian food sector is getting closer to the deadlines for complying with all European Food Safety regulations, the lack of strategic planning among industry players to prepare for these changes and the lack of awareness of the consequences such standards bring could lead to an important reduction in food supplier companies. Despite temporary dispensation, the time has not been used to adjust and adapt to forthcoming standards and especially the milk sector could be facing some important drawbacks. Fees for authorisation, taxes, medical analyses or infrastructure investments will increase financial burden and will put pressure on companies to reorganise their activity in order to remain on the market. Producers and processors are still reluctant to associative forms and try to cope on their own, even though profit margins are low while some even make losses. This in turn outlines another weakness of the food industry namely the lack of a wellestablished, sound and transparent supply chain, which causes operational problems and food safety issues and ultimately leads to a lack of trust within the industry as underlined by Trienekens (2012).

The main and most convenient customer for food processors is the retail sector, because it buys a large amount of products in order to supply their stores and the goods spend less time in warehouses. However there are also downsides for the food processors: the larger amount of goods bought means that the retailer will ask for (and receive) a discount, also the demand volume usually fluctuates and sometimes last-minute orders are received, giving the processor the task to accordingly shift and adjust production levels. Retail stores work with more food processors, which gives the retail stores leverage over their trade partners. Both of them are aware of that, so the stores take advantage of the situation to impose severe contract clauses that swing risk and responsibility mainly towards the upstream part of the supply chain. Amongst them the most common are the low-price pressure, the fluctuating order volumes and the strict delivery deadlines. Regardless, processors prefer to meet initial clauses and accept orders which disrupt their activity both on operational and financial level.

In order to balance benefits and risks two indicators should be considered by the upstream links when negotiating and accepting orders from the retail sector: 
1. Service Rate (SR)

$=$ reflects the company's performance level and is one of the most important efficiency indicators as it is a direct link with the client and should account for a high level of quality and on time deliveries; ideally the indicator should be as close as possible to a level of $100 \%$, but in reality this is seldom possible, thus a level of over $95 \%$ is considered good, but in order to be competitive higher values should be attained.

$$
S R=\frac{N F O}{T N O} * 100[\%]
$$

SR - Service Rate

NFO - Number of Faultless Orders

TNO - Total Number of Orders

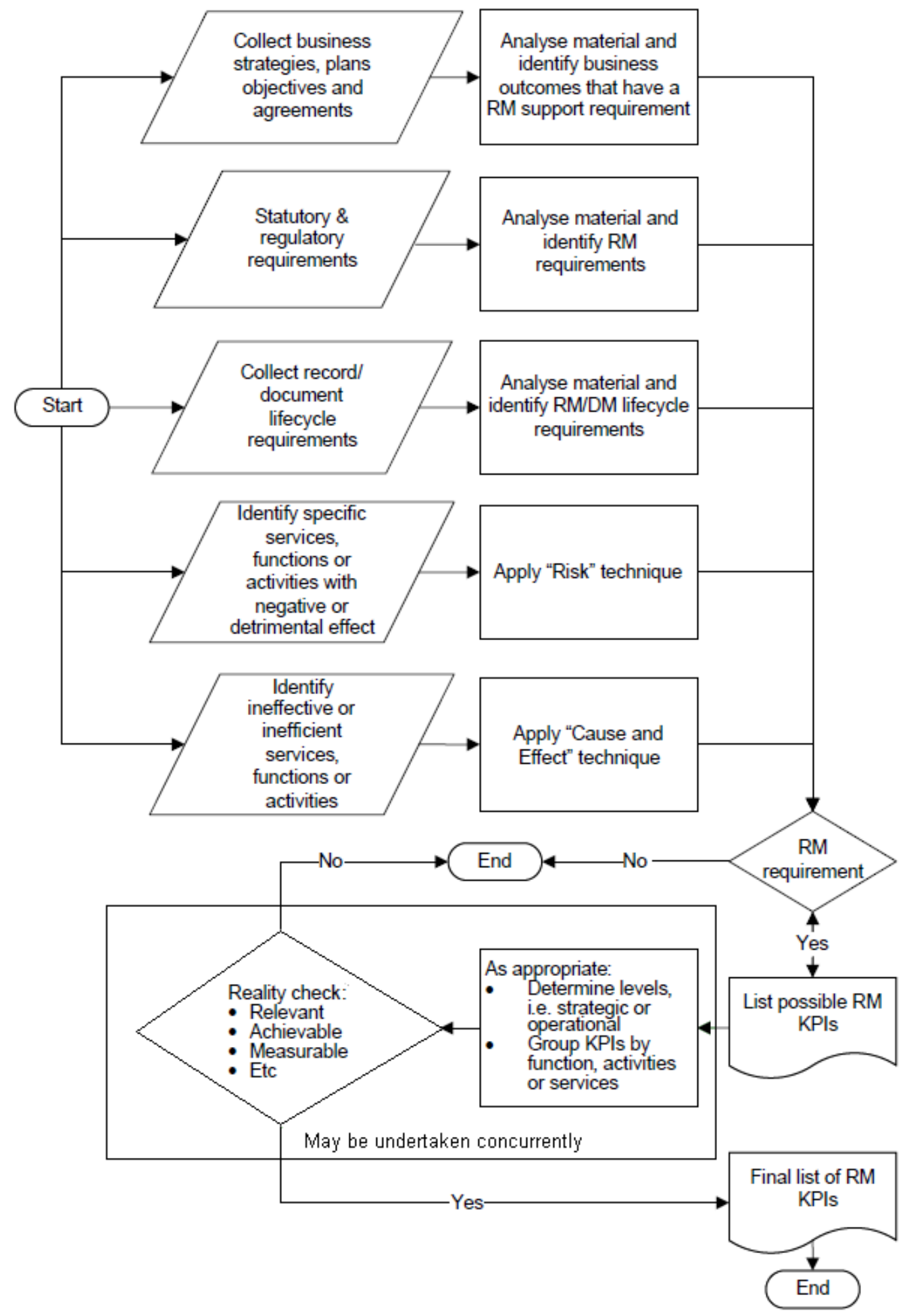

Figure 1. Process for Developing Management KPIs 


\section{Unitary Product Cost (UPC)}

$=$ measures the average costs per unit generated by the company and its operations within a period of time, usually a year; this indicator quantifies the average cost for producing one product or unit and is relevant for efficient pricing.

$$
U P C=\frac{T C}{N P U} * 100[\%]
$$

UPC - Unitary Product Cost

TC - Total Costs

NPU - Number of Produced Units

These indicators are the essence of performance as the first shows to capacity to provide reliable deliveries within complex constraints and conditions, being a more operational-oriented one, whereas the second one is financially-oriented and quantifies the exact unitary amount of cost for each delivered product, giving a clear boundary to processors of their invested effort for the supplied goods. Their relevance for business sustainability is confirmed by Akkerman (2010).

Prior to EU accession Romania's GDP had an impressive trend and while between 2001-2003 the average economic growth was around $5.3 \%$ it improved and rose towards an average of $6.7 \%$ during 2004-2006. Even after Romania entered the EU the ascendant trend of its GDP continued and registered a growth of $6.1 \%$ in 2007 and $7.1 \%$ in 2008.

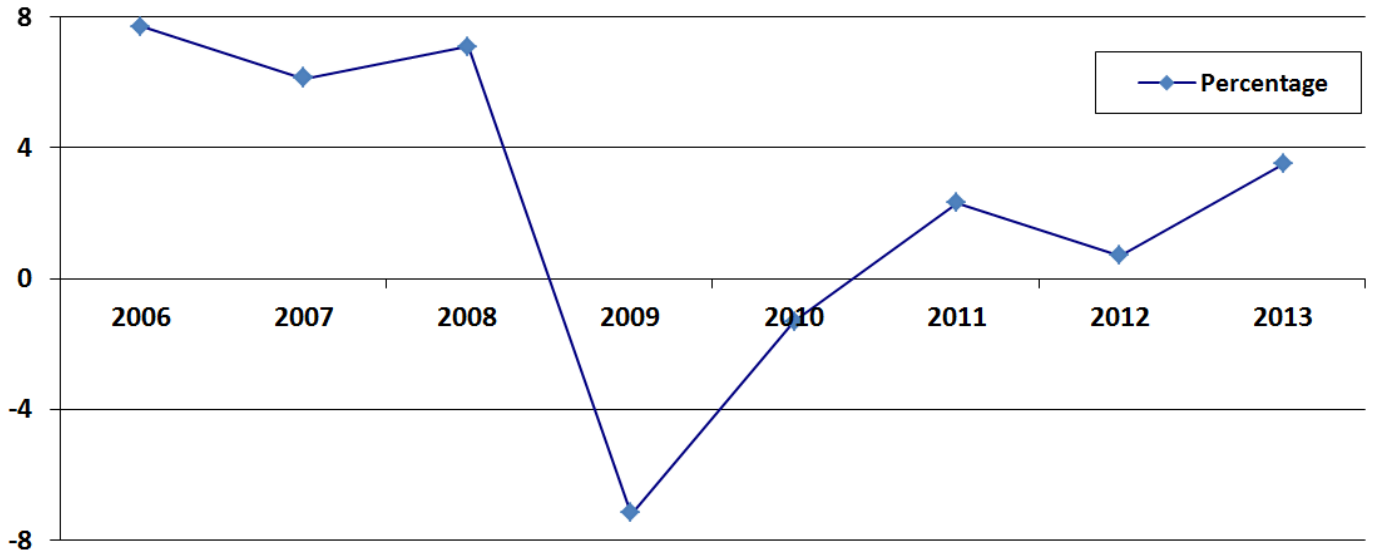

Figure 2. Romania's Annual GDP Growth

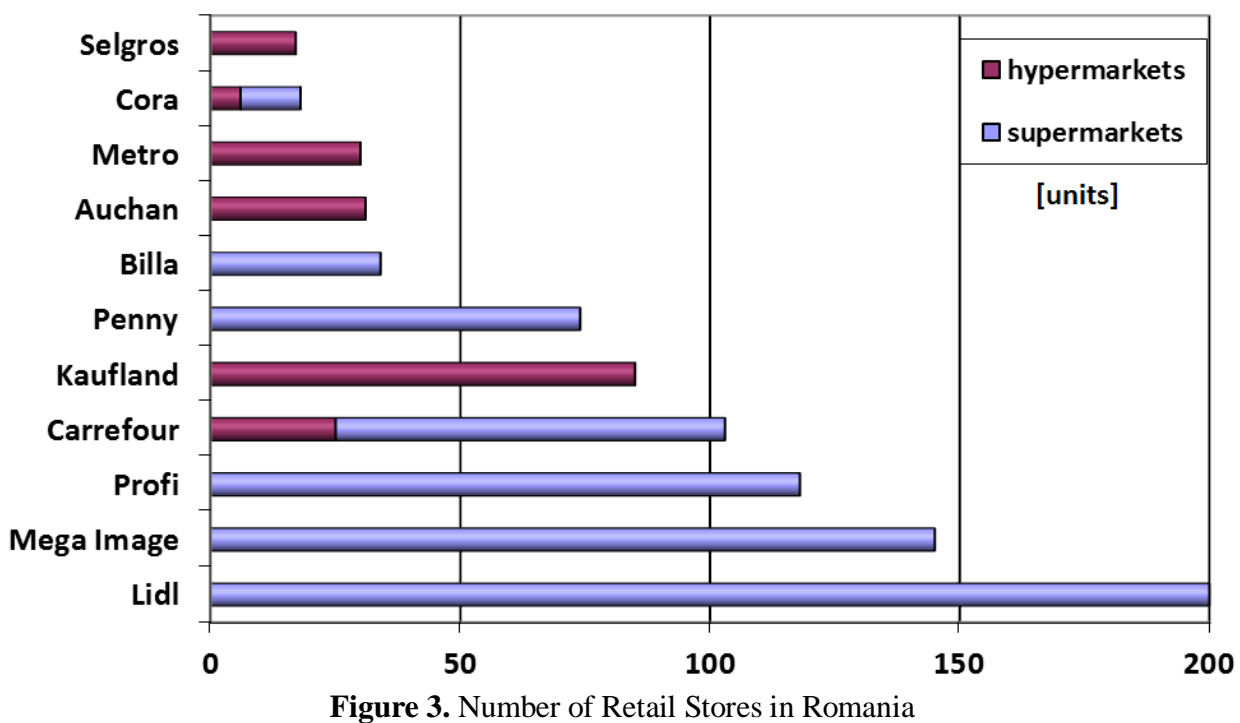

This development was mainly due to internal consumption which was constantly rising and impacted GDP by $10 \%$, closely followed by investments and the construction and real estate sector. Investments in Romania had continued to enter in the economy accounting for $6.6 \%$ of GDP, while the construction sector started to grow with around $10 \%$ every year, boosting the real estate market as well. Although the balance of trade was slightly slowing the economic growth down, forecasts remained optimistic for the following years. However the financial crisis had reversed the trend and the economy plunged in 2009 and contracted by $7.2 \%$. In July 2010 wages within public sector were reduced by $25 \%$ in order to slow down the budget deficit while the economy decreased by a further $1.3 \%$ that year. The main factors that had boosted the economy prior to the crisis were experiencing rough drops as internal consumption contracted by $8.2 \%$ in 2009 and by $2.1 \%$ one year later, while the construction sector decreased by almost one third in just 2 years (17\% in 2009 and 12\% in 2010) and investments were cut down by more than $40 \%$ (29.1\% in 
2009 and $13.5 \%$ in 2010). The national economy recovered in the last years and managed to pick up where it left off, but growth is not as impressive yet: $2.3 \%$ in 2011 and a slight $0.7 \%$ in 2012 whereas last year a good $3.5 \%$ growth was achieved. The former boosting factors of the economy are still experiencing tough times while the turnaround is due to other sectors of the economy as leading factors have shifted and thus taken over in importance and contribution to the country's GDP which in 2013 added up to 140 billion euros according to the National Institute of Statistics.

Encouraged by the economic development recorded in Romania prior to the crisis, several retail brands entered the Romanian market or invested in opening new facilities. Today 838 retail stores of 11 brands operate on the national market and compete to assure their profit margins which are also slowly recovering after a deep plunge during 20092010. The retail sector has also been affected by the recent economic developments as one of the three real,hypermarkets in Timisoara was closed in early 2012 following weak financial results, a first in the industry. Growth is slim and although other brand are still opening supermarkets in some areas, the Romanian market is approaching saturation and thus competition among retailers will mainly be focused on efficiency and pricing policies.

Traditional players still survive due to their capability of fulfilling impulse needs, their higher density and proximity. Their number is however decreasing, not only due to the tough competition from modern retails, but also due to the recent deteriorating economic environment.

The economic growth in Romania of the last 3 years is mainly due to the industry sector (especially car manufacturing industry), good agricultural years and an improvement in the trade deficit through export growth. The country's food market is still characterised by lower per capita incomes and by the existence of a large rural population (with less access to modern retails), which means that the customer base is rather stable while considerable shifts in economic development are still taking time. Internal consumption has slightly increased, but this is not confirmed by official figures due to fact that consumer behaviour have suffered a slight change, especially in the food sector, where people do not necessarily buy less in terms of volume, but they are becoming more and more price-sensitive and thus have shifted towards new consumption habits, mainly oriented towards lower-priced and cheaper goods in the detriment of those of higher quality. An example which clearly confirms this shift in behaviour is the bankruptcy of the Israelian dairy company, Tnuva. Their policy was to make quality dairy products (milk, yoghurt, cheese) that would stand out in the market and thus be attractive to consumers, so they invested around 60 million euros during 2007-2011. They did not manage to make profit in either of those years, thus only 5 years after entering the Romanian dairy market, one of the most important brands with a $5 \%$ market share had declared bankruptcy in early 2012. The exit of Tnuva had an important impact in the market, not only for its 127 employees, but also for its suppliers, who were left without a customer, but also with the issue of unpaid debts. Most of them had then signed contracts with Danone who pressured them to lower their prices to up to $30 \%$ due to a decrease in milk consumption. On the other hand, although Danone had managed to contract most of the former Tnuva suppliers, the decrease in the population's consumption meant the milk collected from them was more than they could sell, so as to avoid a complete loss they would sell it shortly before expiration to other milk processors at less than half of its price. Besides the fact that a constant price reduction implies pressure on companies to cut down costs and affects the entire supply chain, from downstream to upstream, such a tendency also brings about an inevitable decrease in quality and thus slows an economy down in its attempt to achieve wellbeing for its population. Nevertheless positive examples can also be noted within the dairy industry as is the case of Romanian company Albalact with an important $23 \%$ growth of its turnover to around 96 million euros in 2013 and profits of almost 2 million euros last year, a 14\% increase compared to 2012. Albalact is currently the second most important producer of milk and dairy products in Romania after Danone with a turnover of 109 million euros (5\% decrease) and in front of Friesland whose turnover has also decreased to around 82 million euros last year. It employs over 800 people and is listed on the Bucharest Stock Exchange (BVB), being an example that businesses can succeed if they have the capacity to adapt to market conditions.

\subsection{Cash-Flow Disruptions}

Since a large segment of the population, mainly from the rural area, remains too poor to consume significant amounts of processed food products, the retail sector will focus on gaining market shares from its competitors in order to attract more of the existing consumer base. As pricing becomes more and more important and a main condition for competitive advantage, the competition among retail stores will sharpen. Within the sector consumer pressures on prices will lower retail profits and put pressure on lowering costs and improving cost-control effectiveness additionally straining the upstream part of the chain.

Moreover although payment terms are stipulated in the contract between processors and stores, usually ranging 6090 days, stores still try to delay payments by 5-10 days which affects processors even more due to late repayment of interest rates and penalties which weaken the both financial benefits of the agreement and operational performance and cause frantic cash-flow disruptions. Thus food processors either have the capacity to continue work and provide goods with the support of owner's own capital or they await payment due dates in order to finance past activity, which brings about the importance of the following indicator:

\section{On Time Payments within Own Supply Chain (OTPOSC) \\ $=$ reflects the company's ability to keep a healthy} functioning supply chain by sustaining a proper cash-flow movement from its clients and towards its suppliers in a certain period of time; the indicator can also be split in order to show the upstream flow (towards suppliers) and the downstream flow (from customers) separately and values should be as close as possible to a standard $100 \%$ value for businesses effectiveness.

$$
\text { OTPOSC }=\frac{\text { NOTP }}{\text { NIP }} * 100[\%]
$$


OTPOSC - On Time Payments within Own Supply Chain NOTP - Number of On Time Payments

NIP - Number of Issued Payments

According to a study conducted by Coface on 11648 companies (from a total of 163968 food industry companies), around $43 \%$ of food companies have difficulties in meeting payment deadlines with their suppliers and often record slow or irregular payments. Just under $31 \%$ manage to uphold contractual agreements, while over $17 \%$ account for high risk in not being able to repay business partners. When payments are delayed, besides operational issues such as the processors not being able to pay their suppliers, employees start making pressures concerning wages (late payment or salary increase desires) which generates a dysfunctional work atmosphere and alters internal performance. This highlights the importance of the following indicator:

\section{Staff Turnover (ST)}

$=$ measures the capacity of the company to assure a stable workforce and generate sustainable growth both on professional level for employees and for the company through individual and overall productivity; staff turnover can prove positive when ranging between certain limits (around 5\%), but when exceeding certain values the effects can prove very damaging for both company productivity and overall work atmosphere.

$$
S T=\frac{N E H P}{N O P} * 100[\%]
$$

\section{ST - Staff Turnover}

NEHP - Number of Employees Hired within Positions NOP - Number of Positions

These risks could lead to companies being insolvent or actually declaring bankruptcy, therefore generating more problems and distortions. These issues often lead to employees quitting their jobs thus leaving processors in search of qualified workers, which are more and more scarce on the market as a result of the poor industry image, the low-wages and the workforce emigration. The lack of a career perspective drives most people away, adequate and motivated employees being the more and more harder to find, revealing another structural weakness of the food industry.

\subsection{Unbalanced Trade Balance}

Exports are of a high importance for the measure of a country's competitiveness and are among the factors that contribute to economic growth, therefore it is important that they are given a special attention as outlined by Prime (2009) and Hsu (2013). However the balance of trade, the difference between the value of goods exported and those imported, is a more relevant figure as it includes the export figures and also compares them to the value of imports. Usually when a country exports more than it imports (trade surplus) this means that additional money is being added into the economy, being a very important asset in achieving economic growth and having an effect in improving the standard of living through the creation of demand and jobs. When there is a trade deficit (a country imports more than it exports) it usually has the opposite effect of a trade surplus: it has an immediate and indirect effect on a country's GDP by reducing it and is generally a sign of competitiveness issues.

Although Romania has high potential to produce and assure its internal consumption of food products (certain opinions even state that the country has the potential to feed up to 80 million people), structural problems within the industry hamper its competitiveness by a low degree of domestic food products getting distributed towards end consumers, generating waste and losses to industry producers and processors and creating the need to heavily import (up to two-thirds) this kind of goods from abroad. Another problem with the country's balance of trade is the fact that Romania exports a high amount of raw materials (mainly maize, wheat, barley, rape seed and sunflower but also livestock, oilseeds and vegetable oils and fats), which are usually very cheap and thus are not high value added products with a small impact in the global value of exports. On the other hand Romania imports finished goods (mainly pork meat, sugar and processed products but also alcoholic beverages, coffee and fruits and vegetables), which are considerably more expensive than the mere raw material and have more added value and thus have a considerable impact in the total amount of imports.

\section{Unitary Product Profit (UPP)}

$=$ reflects the average benefits per unit generated by the company and its operations within a period of time, also usually a year; a good value depends upon the type of business, a producer will usually want a ratio ranging between $10-15 \%$ to cover costs, whereas a distributor can be satisfied with a ratio of up to $5 \%$ as he gains from a high turnover.

$$
U P P=\frac{T P}{T P U} * 100[\%]
$$

UPP - Unitary Product Profit

TP - Total Profit

NPU - Number of Produced Units

There are some companies who export food products that account for higher added value, but they are very few and represent only a small part within the share of export value. Even during harvest imported goods often have smaller prices than those supplied by the internal market and this although production levels are good and climatic conditions are met for producers to collect a high amount of their crops. As there are lots of small producers, the battle is thought among them to sell their harvest, often at derisory prices, but intermediaries add on extra costs and when they enter the supermarkets the taxes added make the local food products more expensive than the ones from abroad. This is the case when food products actually enter the stores, but most of the times they do not make it that far due to decoupling along the supply chain, either on producerprocessor stage or on processor-intermediary stage (when one of the two partners does not accept conditions and is not open for negotiation) or before entering the stores (where certain specific conditions have to be met in order for deliveries to be accepted). 


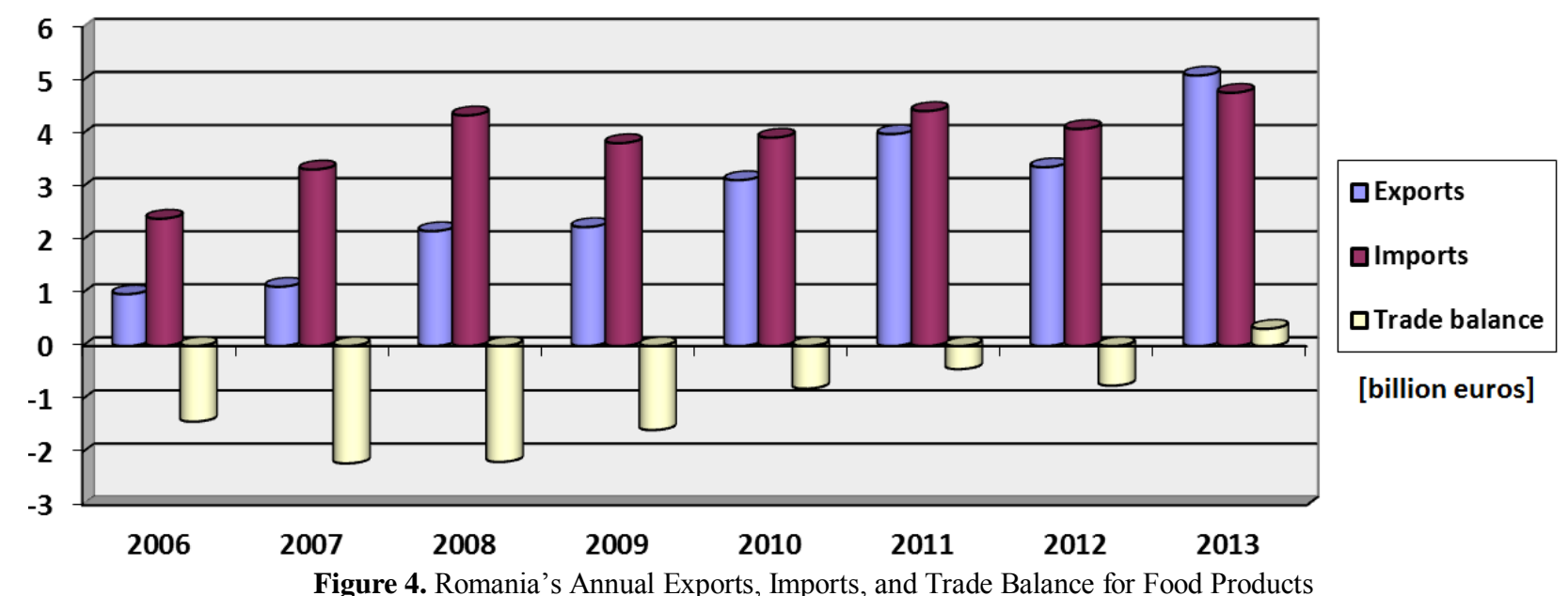

Despite the different nature of goods exported and imported, the balance of trade of agri-food products has improved within the last couple of years and thus had an improved contribution to GDP as between 2008-2012 exports have risen by $55 \%$ whilst imports have decreased by $6 \%$ and the gap between the two slowly closed up. Last year a $30.2 \%$ increase in exports to a total of 5.098 billion euros had finally overcome the $16.6 \%$ growth of imports to 4.773 billion euros, which means that for the first time in 20 years the country achieves a positive trade balance of around 325 million euros, which is a good sign for future development.

\subsection{Taxation and Tax Evasion}

One of the main issues relating to food industry in Romania is the high tax level, regarding workforce taxation but also the value added tax of $24 \%$. A VAT of $24 \%$ is among the highest levels in the EU and when applied to food products these become less accessible to the population as they are more expensive. These taxation issues strains the processors of food industry from both ends of the supply chain and ultimately increase the burden they have to face in order to properly perform their operations. Some EU countries have a reduced VAT (and even extra-reduced VAT for certain types of food products) which applies to food products and thus help the industry perform under more flexible conditions of taxation while in the meantime consumers pay less for their everyday food basket. The UK and Malta even have a $0 \%$ VAT which applies to all food products. On the one hand there is a high burden on wages as an employer pays around $80 \%$ of taxes for each euro of the employees' minimum wage salary. This amount rises to almost $89 \%$ for those employees who work for the average salary. These means the employers' effort actually costs him twice as much as the amount he actually gives to his employees, which raises a discussion of employee performance and the rate of benefits they provide as following:

\section{Profit per Employee (PPE)}

$=$ reflects the average productivity of each employee in terms of benefits provided each year from an employee towards the company; the indicator should be in line with company results and account for steady or growing benefits

$$
P P E=\frac{A P}{A N E} * 100[\%]
$$

PPE - Profit per Employee

AP - Annual Profits

ANE - Average Number of Employees per year

One of the reasons why salaries are low in this sector is that the global performance of the industry is not able to support proper salary increase, while the other refers to the cost of work, which are very high and a decision to raise salaries will put extra pressure on companies from within the industry to cover the raise in wages with a raise in productivity and profits. On the other hand however as downstream supply chain partners are in control and impose price reduction to processors and given the structural issues of Romanian food industry, for most companies it is unlikely that the wage increase will be outreached by productivity and earnings in order to justify such decisions.

Another main issue which puts a lot of pressure on the food industry is tax evasion. Tax evasion is a serious threat to the industry and those who legally compete to produce and supply food products as highlighted by Long (2008), not only to comply with several EU policies, which often request investments or are a financial burden, but also in terms of competitive pricing. If Romanians can buy a certain food product cheaper, they will do so, even if that product has not been subject to specific standards in terms of production and inspection. With some it is a question of trust in the person or place from where they buy such products, with others it is a question of convenience. Both the case, food industry loses money and those who conduct business loose customers, adding an extra challenge to the entire food supply chain. Tax evasion in food industry is estimated by the Romanian Food Industry Federation to be around 50\% with some industries like meat, dairy, milling and bakery or even higher as fruit and vegetables account for a level of up to $70-80 \%$ according to the PRO AGRO National Federation.

\subsection{The Role of Authorities}

Although the tax evasion rates in food industry are known even by officials, inspections however are rather rare and random, so they generally lack efficiency. Sometimes 
the authorities even give legal operating companies a hard time, whereas with those who often failing to comply to standards inspections seem to be more conciliatory. Thus there seems to be another problem which has found its way among the other already present: corruption. Authorities need to be independent and work together with those who are legally conducting business and complying with policies and standards in the industry in order to make food products safer and to assure proper conditions for those who operate in the food industry. Therefore those who do not meet required standards will not be able to continue competing and seizing market shares and customers from legal entities. According to the Romanian Food Compass 2012-2013 conducted by EFMI Business School Romania, managers are mainly concerned by the evolution of raw material prices and the instability of the Eurozone. However $57 \%$ of them are worried about political and legislative instability and $36.5 \%$ specify corruption as a factor that affects their businesses. Corruption is a very dangerous phenomenon and has to be given serious consideration, because if it gets systemic, it will not only affect one industry but it will also threaten others and both the economic development of the country and the standard of living of its population will be severely affected.

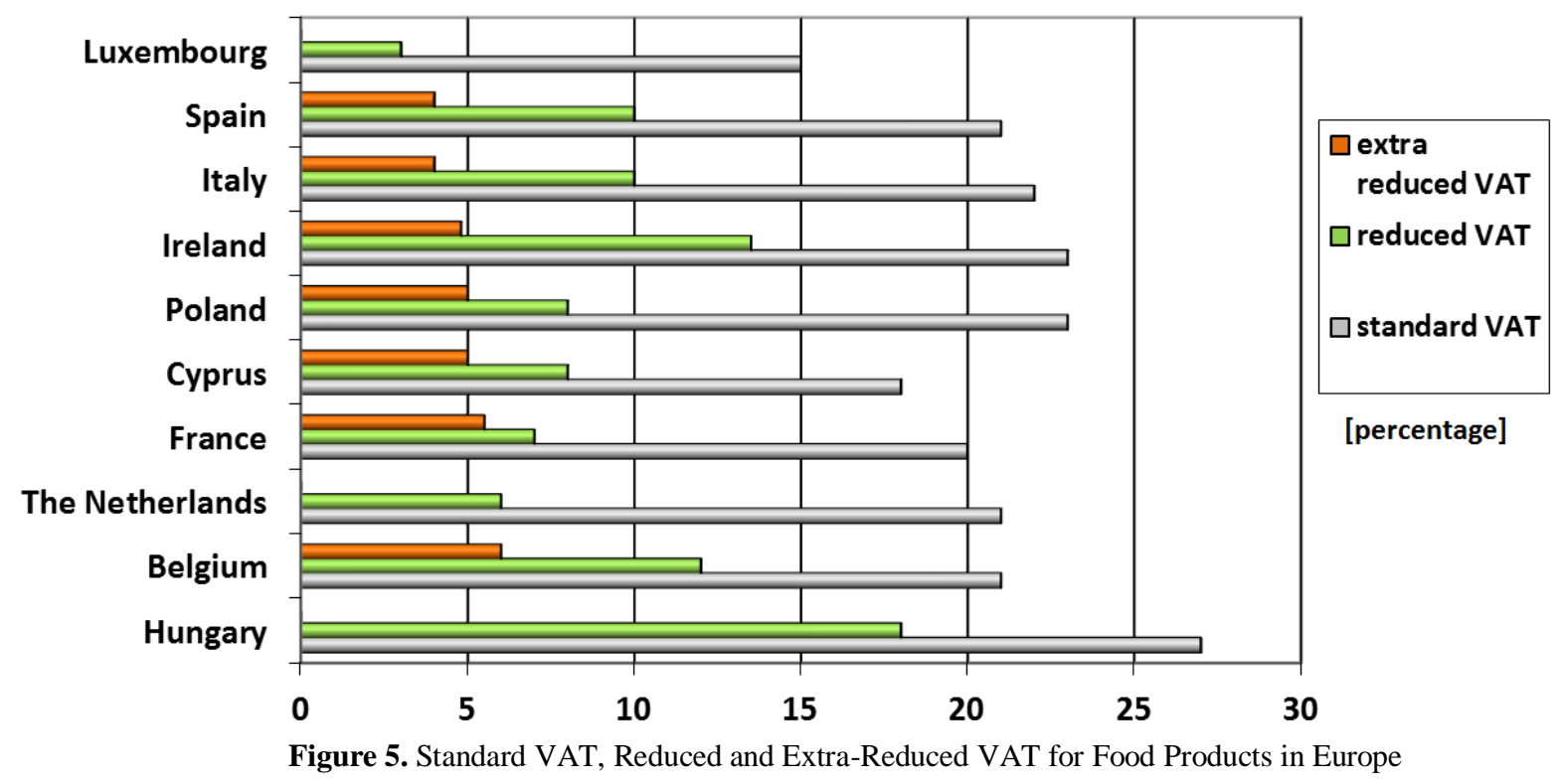

\subsection{Recent Food Scandals}

Besides all these issues the Romanian food industry has also been confronted with both national and international scandals regarding food safety and although these accusations were not confirmed the surging debates and mistrust lead to important losses for the concerned sectors. Early 2013 the Food Safety Authority of Ireland (FSAI) announced that horse meat had been found in frozen beef burgers at several Irish and British supermarkets and initially Romania was accused of being responsible for relabeling horse meat as beef and then passing it through the supply chain before finally entering supermarkets in the UK and Ireland. However these accusations were proven false as Benoit Hamon, French Consumer Affairs Minister, confirmed that the meat that left Romania had been clearly and correctly labelled as horse meat and that the French meat processing company Spanghero was responsible for the relabeling issue and for knowingly selling horse meat as beef and passing it through the supply chain. Following the scandal Spanghero's sanitary license was suspended and then revoked and 8 managers were arrested for aggravated fraud and mislabelling of food products. Moreover the European Commission decided to co-finance by $75 \%$ the DNA testing of meat products to accurately identify the content of meat products and also to strengthen inspections in slaughterhouses, warehouses and in retail establishments to determine whether labelling matches that what is actually sold. However Romanian companies of the meat industry were affected by the scandal and faced a $10 \%$ reduction in internal demand and important export contracts were cancelled.

Less than a month later food safety inspectors found exceeded allowable limits for aflatoxin in milk samples taken from a farm. After several producers and processors announced that milk is contaminated with aflatoxin the authorities began a series of checks on the milk market and almost 200 tonnes were withdrawn from processing or direct sale to end consumer, while more than 100 tons of dairy products were withdrawn from warehouses and destroyed (1.66\% of Romania's monthly production). An assessment of the aflatoxin incident revealed a loss of 20 million euros for the industry, more bad news after official figures of the year 2012 showed a massive $60 \%$ fall in the last 4 years from 2 billion euros in 2008 to only around 800 million euros in 2012, while the volume of dairy products has declined by $20-25 \%$ according to APRIL (The Romanian Dairy Industry Association).

A new scandal erupted in October and affected the poultry industry, one which had performed very well in 2013 by achieving remarkable results in export. In several of its stores, Selgros had refused deliveries of poultry meat from the provider Avicola Calarasi due to its appearance and inappropriate quality and decided to stop any future deliveries until the situation would be clarified. After several checks the National Food Safety Authority (ANSVSA) withdrew a quantity of 55.7 tonnes of poultry meat from sale 
from stores in Bucharest and throughout the country for which there had been a suspicion of it being infected with Salmonella. The poultry meat was supplied by Avicola Calarasi, a company suspected of conducting tax evasion and which was facing liquidation. According to investigations conducted at Avicola Calarasi, the most likely source of contamination has been linked to non-compliance of handling and storage conditions within the food products warehouse. Following this scandal, the poultry sector in Romania recorded in those days losses of more than 25 million euros due to a drop in sales of $20 \%$, while total losses to the industry were estimated at 50-60 million euros.

Meanwhile on international level Russia have banned imports of food products (meat and dairy products, fruit and vegetables) from the EU, USA, Australia, Canada and Norway which will further cause problems for EU food exporters as they will have to find alternatives to supply the amount of products previously provided for the Russian market which accounted for sales of almost 33 billion euros in 2013. This will be a challenge to reorganise capacity planning and assure product distribution whilst remaining competitive both on short and long-term.

\section{DISCUSSION}

By capturing processor margins, retailers cut their risks and costs in order to assure their margins on short and medium term but add extra pressure on processors and producers, making their businesses less profitable, hampering their development and indirectly making the food supply chain unviable in the long term as underlined by Bowman (2013). Effective supply chain management requires careful consideration of multiple tiers of partners, especially with respect to sustainability issues as shown by Grimm (2013). Some recent events (VAT reduction for bakery products to $9 \%$, reopening of pork meat market abroad, policies regarding mutual funds in case of critical situations, financial support for milk cooling tanks) offer a more optimistic perspective for the industry.

Shifting from national underachievement towards international competitiveness requires time and a thorough process of structural change, investments in infrastructure and a new vision which implies collaborative forms, benefits and risk sharing for those who work in the industry as suggested by Beske (2013) and Astuti, Arkeman, Poerwanto and Meuwissen (2013). Meanwhile all supply chain links must improve individual performance by setting up, measuring and analysing results achieved for the six proposed indicators in order to assess progress and performance development on economic and social level as well as within their own supply chain as confirmed by Garcia (2012).

Collaboration is essential throughout the food chain and only through long-term partnerships can all links of the chain benefit from its returns and improve performance as outlined by Thongrattana and Perera, N. (2010). Another way to achieve a sustainable partnership is applied by Transavia in the meat sector who operates an integrated production chain which ranges from the feed up to the distribution of poultry meat. Companies can only improve when they are fully aware of current performance, make efforts to improve and to collaborate within their supply chains as is implied by Prange (2011).
The paper provides a thorough analysis on the current challenges the Romanian food industry is facing and the issues that hamper it to be competitive on both its national market as well as on international markets. The research points out a number of six performance indicators that companies within the food industry can use to regularly assess their internal performance and monitor progress and enables a more sustainable perspective for them on microeconomic level, their supply chain on a wider basis and ultimately the national food industry as also pointed out by Basnet and Wisner (2012).

With an important agricultural background, resources and know-how, Romania has the means to boost its overall performance by taking progressive action to adjust its deficiencies and adapt to European and international standards. The year 2013 has shown that the industry is capable of performing well despite challenging events. However, sustainable competitiveness of the food industry sector can only be achieved through synergic implication of all parties: upstream links (producers and food processors), downstream links (retail stores: hypermarkets and supermarkets) and regulatory links (the Romanian state, associations and authorities). All producers, processors and even retailers have to make an important change and shift towards collaboration, by treating each other as partners rather than mere suppliers, customers or authorities: only by working together and building lasting partnerships based on trust, mutual respect and a common win-win philosophy can Romanian food industry grow and bring benefits to all those who work hard within the complex supply chain to make quality and competitively priced food products available for consumers.

\section{ACKNOWLEDGEMENT}

This paper is supported by the Sectoral Operational Programme Human Resources Development (SOP HRD), ID134378 financed from the European Social Fund and by the Romanian Government.

\section{REFERENCES}

Ahumada, O., Villalobos, J. R. (2009). Application of planning models in the agri-food supply chain: A review. European Journal of Operational Research 196 (1), pp. 1 - 20.

Akkerman, R., Farahani, P., Grunow, M. (2010). Quality, safety and sustainability in food distribution: a review of quantitative operations management approaches and challenges. OR Spectrum 32 (4), pp. 863 - 904.

Astuti, R., Arkeman, M.M.Y., Poerwanto, R., Meuwissen, M.P.M. (2013). Risks and Risks Mitigations in the Supply Chain of Mangosteen: A Case Study. Operations and Supply Chain Management 6 (1), pp. 11-25.

Basnet, C., Wisner, J. (2012). Nurturing Internal Supply Chain Integration. Operations and Supply Chain Management 5 (1), pp. 27-41.

Beske, P., Land, A., Seuring, S. (2013). Sustainable supply chain management practices and dynamic capabilities in the food industry: A critical analysis of the literature. International Journal of Production Economics 152, pp. 131 - 143.

Bowman, A., Froud, J., Johal, S., Leaver, A., Williams, K. (2013). Opportunist dealing in the UK pig meat supply chain: Trader mentalities and alternatives. Accounting Forum 37 (4), pp. 300-314.

Department for Agriculture, Nature and Food Quality Embassy of the Kingdom of the Netherlands (2010) - The Romanian 
food sector and the use of EU Funds for Investments [online] [last accessed 27 August 2014], available at http://www.hollandtrade.ro/download.aspx?file=file/Food sector_report_-_June_2010_v4-draft.pdf.

Garcia, F. A., Marchetta, M. G., Camargo, M., Morel, L., Forradellas, R. Q. (2012). A framework for measuring logistics performance in the wine industry. International Journal of Production Economics 135 (1), pp. $284-298$.

Grimm, J. H., Hofstetter, J. S., Sarkis, J. (2013). Critical factors for sub-supplier management: A sustainable food supply chains perspective. International Journal of Production Economics 152, pp. $159-173$.

Hsu, C., Lien, Y., Chen, H. (2013). International ambidexterity and firm performance in small emerging economies. Journal of World Business 48 (1), pp. 58 - 67.

Lavie, D. (2006). The competitive advantage of interconnected firms: An extension of the resource-based view. Academy of Management Review 31 (3), pp. 638 - 658.

Long, B. S., Driscoll, C. (2008). Codes of ethics and the pursuit of organisational legitimacy: Theoretical and empirical contributions. Journal of Business Ethics 77 (2), pp. 173 189.

Prange, C., Verdier, S. (2011). Dynamic capabilities, internationalization processes and performance. Journal of World Business 46 (1), pp. 126 - 133.

Prime, N., Obadia, C., Vida, I. (2009). Psychic distance in exporter-importer relationships: A grounded theory approach. International Business Review 18 (2), pp. 184 198.
Reh, F. H. (2009). Key Performance Indicators (KPI), How an organization defines and measures progress toward its goals [online] [last accessed 27 August 2014], available at http://management.about.com/cs/generalmanagement/a/key perfindic.htm

Rong, A., Akkerman, R., Grunow, M. (2011). An optimization approach for managing fresh food quality throughout the supply chain. International Journal of Production Economics 131 (1), pp. $421-429$.

Thongrattana, P.T., Perera, N. (2010). Perceived Environmental Uncertainty Along the Thai Rice Supply Chain: An Empirical Approach. Operations and Supply Chain Management 3 (3), pp. 117-133.

Trienekens, J. H., Wognum, P. M., Beulens, A. J. M., van der Vorst, J. G. A. J. (2012). Transparency in complex dynamic food supply chains. Advanced Engineering Informatics 26 (1), pp. $55-65$.

Trienekens, J., Zuurbier, P. (2008). Quality and safety standards in the food industry, developments and challenges. International Journal of Production Economics, pp. 113 (1), $107-122$.

Van Donk, D. P., Akkerman, R., Van der Vaart, T. (2008). Opportunities and realities of supply chain integration: the case of food manufacturers British Food Journal 110 (2), pp. $218-235$

Professor Marian Mocan, born on October 23rd, 1961 graduated from the Faculty of Mechanics in 1986. He obtained the Master Business Counselor title at Washington State University SBDC and a PhD in Economics from the West University of Timisoara. He is the Dean of the Faculty of Management in Production and Transportation of the Politehnica University from Timisoara, Romania. He teaches the Basics of management, Logistics, Strategic management and the Management of logistic systems. He collaborates with universities from Europe, Asia and North America. He is a PhD supervisor in the field of Engineering and management since 2010. He has written 14 academic books and over 140 scientific articles. Research areas of interest are Logistics and Supply Chain Management, Strategic Management, Operational Management.

Attila Turi, born on April 6th, 1987 graduated from the Faculty of Management in Production and Transportation in 2010 and obtained his Master's degree in Logistics from the Faculty of Applied Sciences within the Artois University, France, in 2012. Within the same year he successfully completed the Basics of Supply Chain Management (BSCM) Module and obtained the certification after an exam hosted by APICS. He is currently a PhD student at the Politehnica University from Timisoara, Romania and teaches Industrial and commercial logistics since 2014 and has written 7 scientific articles. His research areas of interest include Performance analysis in the automotive industry, Management, Supply Chain Management and Logistics.

Gilles Goncalves, born on January 11th, 1956 is a full professor at the Artois University, France, since 1994. He studied Computer Science at the University of Lille1 and obtained his PhD in 1985. During 14 years, he was a lecturer and his works concerned parallel and distributed computing. His current research interests include Information systems, Security management, Simulation modeling, Discrete optimization and Metaheuristics. He has written about 20 papers in scientific journals, 5 book chapters and more than 100 scientific communications in conferences. He manages a research laboratory named "LGI2A", whose main topics are the Organization and management of logistic processes. Sustainable aspects of the supply chain are taken into account in his works.

Sorin-Ioan Maistor, born on October 31st, 1985 graduated from the Faculty of Management in Production and Transportation in 2009. In 2011 he obtained the title of Master in Business Administration (MBA) at the Politehnica University of Timisoara, Romania and is currently a $\mathrm{PhD}$ student in the field of Engineering and management. He began his teaching activity in 2009, as an assistant teacher of Economic engineering, Logistics and Maintenance of production systems within the graduated faculty. He has published 15 scientific articles and is co-author of a guide for seminar activities for Economic and financial analysis. Research areas of interest are Logistics and Supply Chain Management, Production Management and Economic Engineering. 